\title{
Preparation and Chromatographic Characteristics of Calix[4]arene Polysiloxane as Stationary Phases for Capillary Gas Chromatography
}

by X. H. Lai/ L. Lin / C. Y, Wu

published in Vol. 50, 82-88 (1999)

There were errors in two tables. Below please find the correct versions of the tables.

Page 83:

Table I. Characteristics of capillary columns

\begin{tabular}{|c|c|c|c|c|c|c|}
\hline Column & $\begin{array}{l}\text { Stationary } \\
\text { phases }\end{array}$ & $\begin{array}{c}\text { Column } \\
\text { dimension/ } \\
(\mathrm{m} \times \mathrm{mm})\end{array}$ & 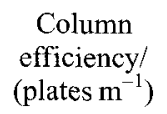 & $\begin{array}{l}\text { Capacity } \\
\text { factor } \\
(k)\end{array}$ & $\begin{array}{c}\text { Peak } \\
\text { asymmetry } \\
\text { factor }\end{array}$ & $\begin{array}{c}\text { Membrane } \\
\text { thickness/ } \\
\quad(\mu \mathrm{m})\end{array}$ \\
\hline $\mathbf{I}$ & PSO-C[4]A & $15.0 \times 0.25$ & 3268 & 3.90 & 1.05 & 0.31 \\
\hline II & PSO-C[4]B & $15.0 \times 0.25$ & 4852 & 3.98 & 1.07 & 0.31 \\
\hline III & M-C [4]A-PSO & $15.0 \times 0.25$ & 2548 & 6.02 & 1.02 & 0.31 \\
\hline IV & $\mathrm{M}-\mathrm{C}[4] \mathrm{B}-\mathrm{PSO}$ & $15.0 \times 0.25$ & 1420 & 3.25 & 1.03 & 0.31 \\
\hline
\end{tabular}

Page 85:

Table IV. Relative retention values $(\alpha)$ of positional isomers in various columns

\begin{tabular}{|c|c|c|c|c|c|c|c|c|c|}
\hline \multirow[t]{2}{*}{ Compound } & & \multicolumn{2}{|c|}{ PSO-C[4]A } & \multicolumn{2}{|c|}{ PSO-C[4]B } & \multicolumn{2}{|c|}{ M-C[4]A-PSO } & \multicolumn{2}{|c|}{$\mathrm{M}-\mathrm{C}[4] \mathrm{B}-\mathrm{PSO}$} \\
\hline & & $\alpha$ & $\mathrm{Tc}\left({ }^{\circ} \mathrm{C}\right)$ & $\alpha$ & $\operatorname{Tc}\left({ }^{\circ} \mathrm{C}\right)$ & $\alpha$ & $\operatorname{Te}\left({ }^{\circ} \mathrm{C}\right)$ & $\alpha$ & $\operatorname{Tc}\left({ }^{\circ} \mathrm{C}\right)$ \\
\hline Benzenediol & $\begin{array}{c}\mathrm{o} \\
\mathrm{m} \\
\mathrm{p}\end{array}$ & $\begin{array}{l}1.00 \\
1.70 \\
1.43\end{array}$ & 200 & $\begin{array}{l}1.00 \\
1.66 \\
1.32\end{array}$ & 170 & $\begin{array}{l}1.00 \\
1.44 \\
1.27\end{array}$ & 170 & $\begin{array}{l}1.00 \\
1.60 \\
1.48\end{array}$ & 160 \\
\hline Nitrophenol & $\begin{array}{c}o \\
\mathrm{~m} \\
\mathrm{p}\end{array}$ & $\begin{array}{l}1.00 \\
5.69 \\
13.3\end{array}$ & 190 & $\begin{array}{l}1.00 \\
3.66 \\
4.75\end{array}$ & 210 & $\begin{array}{l}1.00 \\
4.94 \\
6.58\end{array}$ & 190 & $\begin{array}{l}1.00 \\
5.62 \\
7.55\end{array}$ & 190 \\
\hline Dinitro-benzene & $\begin{array}{l}o \\
\mathrm{~m} \\
\mathrm{p}\end{array}$ & $\begin{array}{l}1.68 \\
1.21 \\
1.00\end{array}$ & 170 & $\begin{array}{l}1.05 \\
1.24 \\
1.00\end{array}$ & 170 & $\begin{array}{l}1.00 \\
1.14 \\
1.32\end{array}$ & 170 & $\begin{array}{l}1.00 \\
1.09 \\
1.22\end{array}$ & 170 \\
\hline Methylnaphthalene & $\begin{array}{l}\alpha \\
\beta\end{array}$ & $\begin{array}{l}1.11 \\
1.00\end{array}$ & 170 & $\begin{array}{l}1.11 \\
1.00\end{array}$ & 170 & $\begin{array}{l}1.14 \\
1.00\end{array}$ & 170 & $\begin{array}{l}1.11 \\
1.00\end{array}$ & 150 \\
\hline Phenanthrene & & 1.00 & 190 & 1.00 & 190 & 1.00 & 190 & 1.00 & 190 \\
\hline Anthracene & & 1.08 & & 1.06 & & 1.02 & & 1.02 & \\
\hline
\end{tabular}

